\title{
Synthesis and characterization of spinel-type $\mathrm{CuAl}_{2} \mathrm{O}_{4}$ nanocrystalline by modified sol-gel method
}

\author{
Masoud Salavati-Niasari · Fatemeh Davar • \\ Masoud Farhadi
}

Received: 29 November 2008/Accepted: 2 March 2009/Published online: 17 March 2009

(c) The Author(s) 2009. This article is published with open access at Springerlink.com

\begin{abstract}
Nanocrystalline Copper aluminate $\left(\mathrm{CuAl}_{2} \mathrm{O}_{4}\right)$ was prepared by sol-gel technique using aluminum nitrate, copper nitrate, diethylene glycol monoethyl ether and citric acid were used as precursor materials. This method starts from of the precursor complex, and involves formation of homogeneous solid intermediates, reducing atomic diffusion processes during thermal treatment. The formation of pure crystallized $\mathrm{CuAl}_{2} \mathrm{O}_{4}$ nanocrystals occurred when the precursor was heat-treated at $600{ }^{\circ} \mathrm{C}$ in air for $2 \mathrm{~h}$. The stages of the formation of $\mathrm{CuAl}_{2} \mathrm{O}_{4}$, as well as the characterization of the resulting compounds were done using thermo-gravimetric analysis, X-ray diffraction, scanning electron microscopy and Fourier transform infrared spectroscopy. The products were analyzed by transmission electron microscopy and ultraviolet-visible (UV-Vis) spectroscopy to be round, about $17-26 \mathrm{~nm}$ in size and $E_{\mathrm{g}}=2.10 \mathrm{eV}$.
\end{abstract}

Keywords Powders-chemical preparation $\cdot \mathrm{CuAl}_{2} \mathrm{O}_{4}$. Nanocrystals $\cdot$ Sol-gel $\cdot$ Transition metal oxides

\section{Introduction}

Aluminum-based spinels constitute an interesting class of oxide ceramics with important technological applications. The impressive optical (e.g., $\mathrm{CoAl}_{2} \mathrm{O}_{4}$ is well known as

M. Salavati-Niasari $(\bowtie) \cdot$ F. Davar $\cdot$ M. Farhadi Institute of Nano Science and Nano Technology, University of Kashan, P.O. Box. 87317-51167, Kashan, I. R. Iran e-mail: salavati@kashanu.ac.ir

M. Salavati-Niasari · F. Davar

Department of Chemistry, Faculty of Science, University of Kashan, P.O. Box. 87317-51167, Kashan, I. R. Iran
Thenard's Blue) and chemical (catalytic applications) properties of transition-metal aluminates make them of significant interest as nano-pigment and catalysts [1, 2]. For example spinel $\mathrm{AMn}_{2} \mathrm{O}_{4}(\mathrm{~A}=\mathrm{Cu}, \mathrm{Zn})$ [3] has been performed well for photocatalyzing water splitting into $\mathrm{H}_{2}$ and $\mathrm{O}_{2}$. Also, studies of aluminate system have focused on doping with the second activator, such as $\mathrm{Nd}, \mathrm{Eu}$ and codoped with Er or Cr [4-6] that these studies are interesting.

Transition metal aluminates are commonly prepared by a solid state reaction [7], coprecipitation method [8, 9], hydrothermal [10-12], combustion [13] and sol-gel [1422]. The disadvantages of solid-state routes, such as inhomogeneity, lack of stoichiometry control, high temperature and low surface area, are improved when the material is synthesized using a solution-based method. Compared with other techniques, the sol-gel method is a useful and attractive technique for the preparation of aluminate spinels because of its advantage of producing pure and ultrafine powders at low temperatures.

Transition metal-oxide spinels are important in many application fields because of their high thermal resistance and catalytic, electronic and optical properties. They are commonly used in semiconductor and sensor technology as well as in heterogeneous catalysis [23-31]. A modified solgel method for preparing the metal oxides is Pechini method [32]. The Pechini method involves combining a metal precursor with water, citric acid and a polyhydroxyalcohol, such as ethylene glycol.

In the present investigation, $\mathrm{CuAl}_{2} \mathrm{O}_{4}$ nanocrystals have been prepared by modified Pechini method. Characterization studies have been done by using thermo-gravimetric analysis (TGA), X-ray diffraction (XRD), scanning electron microscopy (SEM), transmission electron microscopy (TEM), Fourier transform infrared (FTIR) spectroscopy and ultraviolet-visible (UV-Vis) spectroscopy. 


\section{Experimental}

\subsection{Synthesis of $\mathrm{CuAl}_{2} \mathrm{O}_{4}$ nanocrystals}

At first $1.57 \mathrm{mmol} \mathrm{Cu}\left(\mathrm{NO}_{3}\right)_{2} \cdot 3 \mathrm{H}_{2} \mathrm{O}$ were dissolved in $6 \mathrm{~mL}$ diethylene glycol monoethyl ether (DGME) and $23.5 \mathrm{mmol}$ anhydrous citric acid $\left(\mathrm{HOOCCH}_{2} \mathrm{C}(\mathrm{OH})\right.$ $\left.(\mathrm{COOH}) \mathrm{CH}_{2} \mathrm{COOH}\right)$ was subsequently added to this solution and dissolved at $50{ }^{\circ} \mathrm{C}$ for $1 \mathrm{~h}$. After complete dissolution, $3.14 \mathrm{~mol} \mathrm{Al}\left(\mathrm{NO}_{3}\right)_{3} \cdot 9 \mathrm{H}_{2} \mathrm{O}$ in $9 \mathrm{~mL}$ diethylene glycol monoethyl ether was added. A green blue solution was obtained and further heated at $80^{\circ} \mathrm{C}$ for $1 \mathrm{~h}$ to remove excess water. During continued heating at $130{ }^{\circ} \mathrm{C}$ for $1 \mathrm{~h}$, the solution became more and more viscous and finally became a xerogel. To complete drying, xerogel was placed at $250{ }^{\circ} \mathrm{C}$ for $1 \mathrm{~h}$. Result violet powder is as precursor. In the furnace, we heat-treated the precursor at $400-800{ }^{\circ} \mathrm{C}$ in air, in an $\mathrm{Al}_{2} \mathrm{O}_{3}$ boat, and then cooled it to room temperature (Fig. 1). Two processes were adopted to prepare $\mathrm{CuAl}_{2} \mathrm{O}_{4}$ nanocrystals, one process as summarized in Fig. 1 and another process was similar to Fig. 1 only the reaction was done without citric acid.

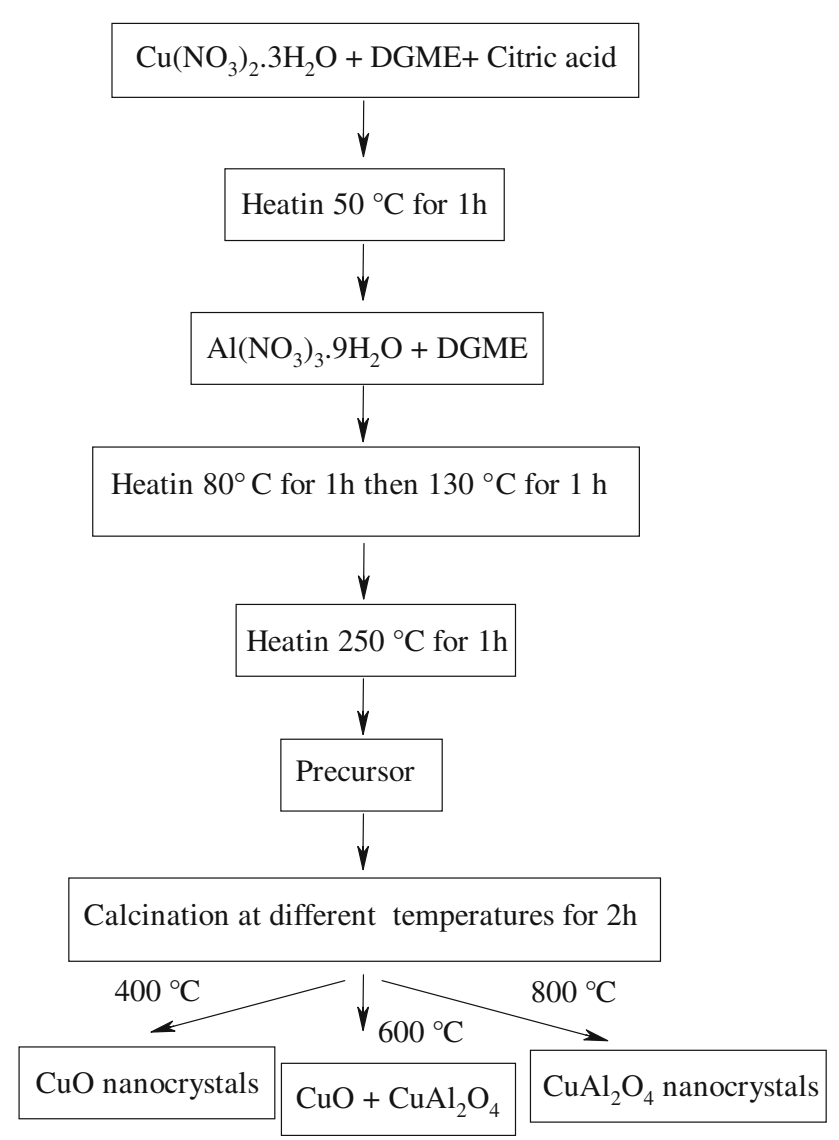

Fig. 1 Preparation of the $\mathrm{CuAl}_{2} \mathrm{O}_{4}$ nanocrystals

\subsection{Characterizations}

All the chemicals reagents used in our experiments were of analytical grade and were used as received without further purification. XRD patterns were recorded by a Rigaku D-max C III, X-ray diffractometer using Ni-filtered $\mathrm{Cu} \mathrm{K} \alpha$ radiation. Elemental analyses were obtained from Carlo ERBA Model EA 1108 analyzer. Scanning electron microscopy (SEM) images were obtained on Philips XL-30ESEM equipped with an energy dispersive X-ray spectroscopy. Transmission electron microscopy (TEM) micrographs were obtained on a Philips EM208 transmission electron microscope with an accelerating voltage of $100 \mathrm{kV}$. Fourier transform infrared (FT-IR) spectra were recorded on Shimadzu Varian 4300 spectrophotometer in $\mathrm{KBr}$ pellets. Ultraviolet-Visible (UV-Vis) spectroscopies for the spectral dependence of optical absorbance for the nanocrystalline $\mathrm{CuAl}_{2} \mathrm{O}_{4}$ powders were taken using spectrophotometer (Model $2101 \mathrm{PC}$ ) equipment in absorbance. Thermogravimetric analysis (TGA) were carried out using a thermal gravimetric analysis instrument (Shimadzu TGA$50 \mathrm{H}$ ) with a flow rate of $20.0 \mathrm{~mL} \mathrm{~min}^{-1}$ and a heating rate of $10{ }^{\circ} \mathrm{C} \min ^{-1}$.

\section{Results and discussion}

The TGA curve of $\mathrm{CuAl}_{2} \mathrm{O}_{4}$ is shown in Fig. 2. The total weight loss was about $90 \%$ of the total precursor mass and occurred in two steps. The first weight loss occurs at about $110{ }^{\circ} \mathrm{C}$, which corresponds to the evaporation of adsorbed water. The second weight loss step occurs at the temperature range $300-580{ }^{\circ} \mathrm{C}$. The weight loss at $300-580{ }^{\circ} \mathrm{C}$ may be ascribed to the decomposition of the organic

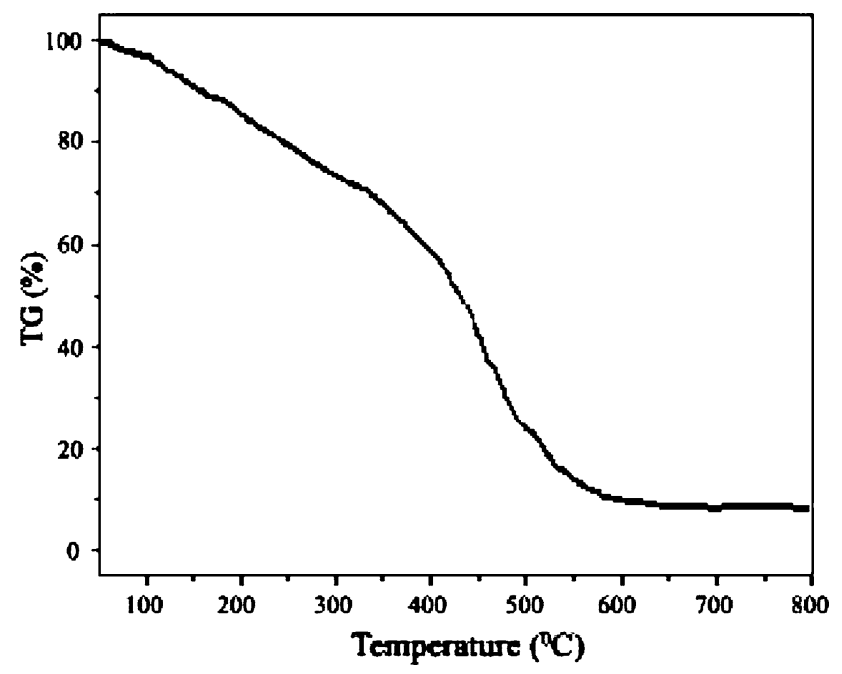

Fig. 2 Thermal gravimetric analyses curve of $\mathrm{CuAl}_{2} \mathrm{O}_{4}$ precursor material 
compound. From $580{ }^{\circ} \mathrm{C}$ was not observed more weight loss, suggesting the formation of a stable oxide, due to spinel-type $\mathrm{CuAl}_{2} \mathrm{O}_{4}$ nanocrystalline present thermal stability at highest temperatures.

Figure 3 showed the XRD patterns of samples as a function of annealing temperatures. In order to restrict crystallite growth, the calcination times at a fixed heating rate were carefully monitored to keep them as short as possible. The precursor powders heat treated at low temperature $\left(400{ }^{\circ} \mathrm{C}\right.$ for $\left.2 \mathrm{~h}\right)$ presents diffraction peaks of copper oxide $(\mathrm{CuO})$ phase with monoclinic structure, in agreement with the literature [32-36] and the respective JCPDS 45-0937 [37]. The diffraction peaks were analyzed and showed the powders form $\mathrm{CuO}$ crystal after annealed at $400{ }^{\circ} \mathrm{C}$ (see Fig. 3a) [32, 33]. However, the XRD pattern exhibited the weak (220), (311) reflection $(2 \theta=31.25$, 37.10) of the spinel form of $\mathrm{CuAl}_{2} \mathrm{O}_{4}$ after annealed at $500{ }^{\circ} \mathrm{C}$ (see Fig. 3b), and consisted only spinel peaks of $\mathrm{CuAl}_{2} \mathrm{O}_{4}$ after annealed temperature of 600 and $800{ }^{\circ} \mathrm{C}$ (Fig. 3c, d). When annealed at $800{ }^{\circ} \mathrm{C}$, the spinel $\mathrm{CuAl}_{2} \mathrm{O}_{4}$ crystals growth larger and the corresponding diffraction peaks became stronger. The diffractograms of two samples (prepared with citric acid and without citric acid) calcined at $800{ }^{\circ} \mathrm{C}$ as shown in Fig. $3 \mathrm{~d}$ and e indicate that each sample is a monophasic spinel cubic $(F d-3 m$ with lattice size of $8.064 \AA$, JCPDS 01-1153).

Yanyan et al. [34] have synthesized nanocrystalline spinel $\mathrm{CuAl}_{2} \mathrm{O}_{4}$ powders by sol-gel method. They could prepare pure spinel $\mathrm{CuAl}_{2} \mathrm{O}_{4}$ nanopowders at $800{ }^{\circ} \mathrm{C}$ according to XRD pattern. They believed spinel $\mathrm{CuAl}_{2} \mathrm{O}_{4}$ is formed at high temperature and at the low temperature only $\mathrm{CuO}$ is formed not $\mathrm{CuAl}_{2} \mathrm{O}_{4}$. Our XRD patterns are agreement with their results.

For two samples substantial crystallinity was achieved at $800{ }^{\circ} \mathrm{C}$ after calcination of the amorphous raw product for $2 \mathrm{~h}$. However, crystallization was also possible at $800{ }^{\circ} \mathrm{C}$ temperatures. No peak sequence that can be attributed either to copper oxide or other impurity could be found in the XRD pattern of the precursor. From XRD data Fig. 3d, the crystallite size $\left(D_{\mathrm{c}}\right)$ of as-prepared $\mathrm{CoAl}_{2} \mathrm{O}_{4}$ particles calcined at $800{ }^{\circ} \mathrm{C}$ for $2 \mathrm{~h}$ was calculated to be $17 \mathrm{~nm}$ using the Debey-Scherrer equation [38],

$D_{\mathrm{c}}=\frac{K \lambda}{\beta \cos \theta}$

where $\beta$ is the breadth of the observed diffraction line at its half-intensity maximum, $K$ is the so-called shape factor, which usually takes a value of about 0.9 , and $\lambda$ is the wavelength of X-ray source used in XRD.

The XRD pattern of the nanocrystals formed in the absence of citric acid shows a relatively sharp peak with higher intensity (Fig. 3e). When citric acid was introduced into the system, the organic ligand capped the nanocrystals

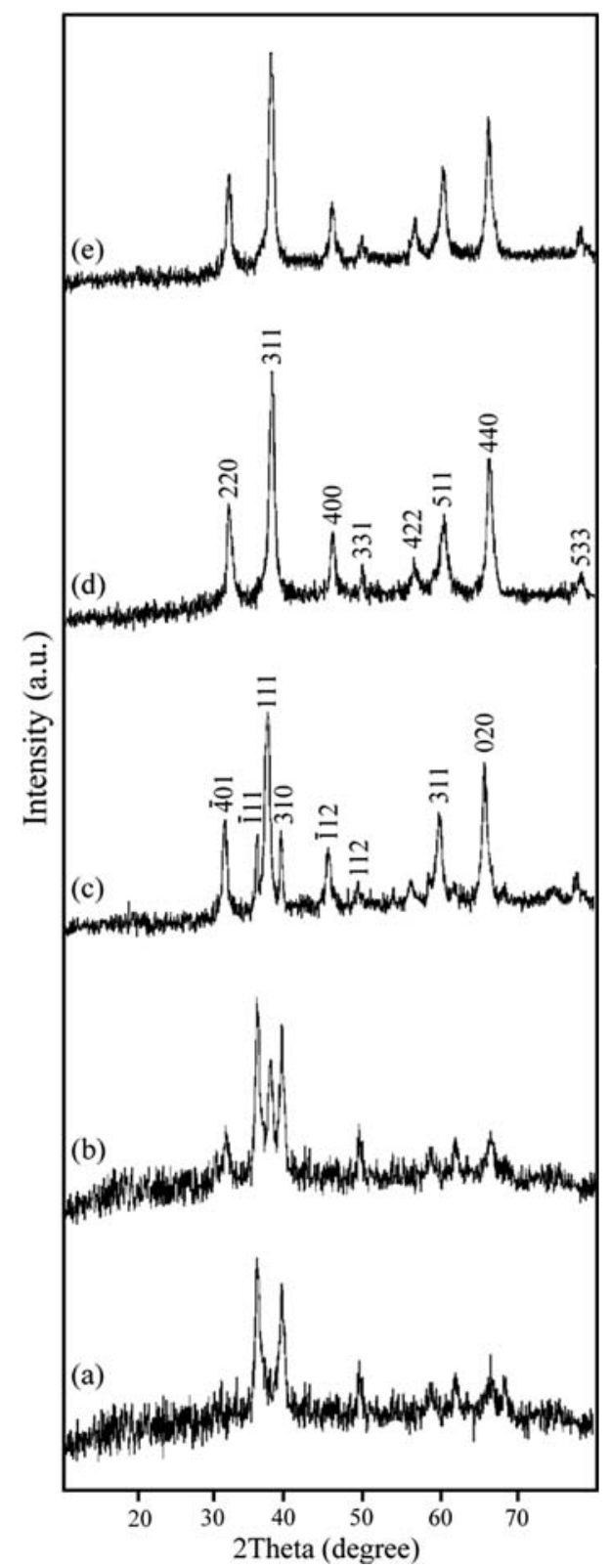

Fig. 3 XRD patterns of $\mathrm{CuAl}_{2} \mathrm{O}_{4}$ powders obtained on heating the precursor in air for $2 \mathrm{~h}$ at (a) $400{ }^{\circ} \mathrm{C}$, (b) $500{ }^{\circ} \mathrm{C}$, (c) $600{ }^{\circ} \mathrm{C}$, (d) $800{ }^{\circ} \mathrm{C}$ with citric acid and (e) $800{ }^{\circ} \mathrm{C}$ without citric acid

surface, thereby inhibiting the growth of the particles. The XRD patterns of the nanocrystals modified with citric acid indicate that the intensity of all of the peaks decreased with a peak broadening (Fig. 3d). This suggests that the size of the nanocrystals was decreased with organic ligand capping. The average crystallite size of the unmodified nanocrystals calculated by the XRD data using Scheerer's equation is $28 \mathrm{~nm}$, while the average crystallite size of nanocrystals synthesized with citric acid modification is about $17 \mathrm{~nm}$.

The surface morphology of the obtained $\mathrm{CuAl}_{2} \mathrm{O}_{4}$ nanocrystals was investigated by scanning electron microscopy images (SEM). Figure $4 \mathrm{a}, \mathrm{b}$ shows the SEM 

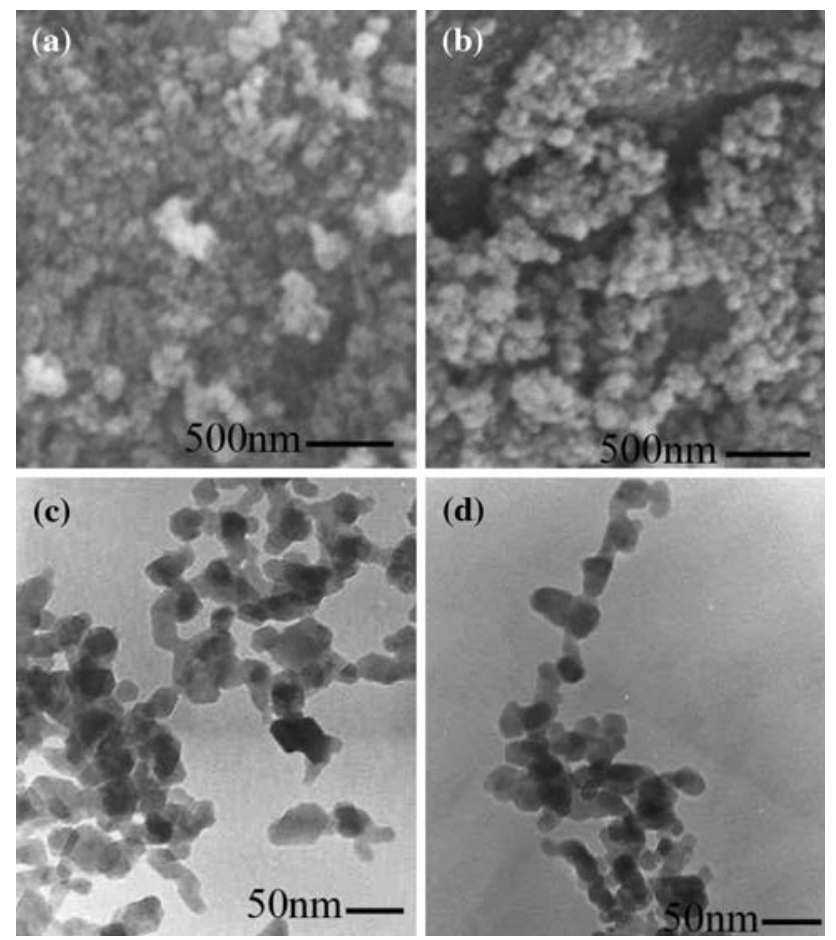

Fig. 4 a, b SEM and c, d TEM images of $\mathrm{CuAl}_{2} \mathrm{O}_{4}$ powders calcined at $800{ }^{\circ} \mathrm{C}(\mathbf{a}, \mathbf{b}$ the sample obtained with citric acid and $\mathbf{c}, \mathbf{d}$ without citric acid)

images of prepared product in the presence of citric acid and without citric acid, respectively. TEM images of $\mathrm{CuAl}_{2} \mathrm{O}_{4}$ nanocrystals are shown in Fig. $4 \mathrm{c}$, d. The images indicate that $\mathrm{CuAl}_{2} \mathrm{O}_{4}$ powder consists of nanometric particles with the diameter of $17-26$ and $12-29 \mathrm{~nm}$ for the nanocrystals modified with citric acid and unmodified nanocrystals, respectively, which is in good with XRD. From the TEM images, we can further confirm that nanocrystals with cubic morphology were obtained by using the organic ligand-assisted thermal treatment approach.

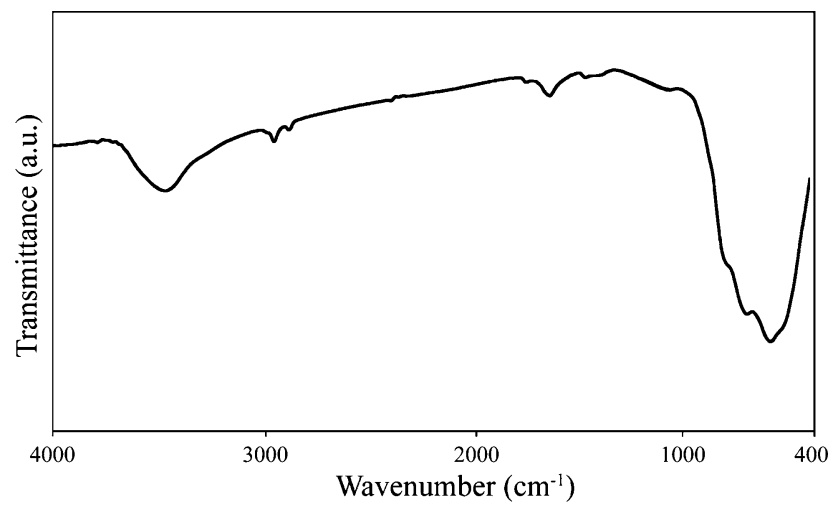

Fig. 5 FTIR spectra of $\mathrm{CuAl}_{2} \mathrm{O}_{4}$ nanocrystals prepared with citric acid and calcined at $800{ }^{\circ} \mathrm{C}$
FTIR measurements (Fig. 5) were used to identify and characterize the resulting spinel nanocrystals. Analyzing the absorption peak around $3,500-3,100 \mathrm{~cm}^{-1}$ was due to the $\mathrm{OH}$ longitudinal vibration of the water, the absorption peak at $1,624 \mathrm{~cm}^{-1}$ belonged to bending vibration of $\mathrm{H}-\mathrm{O}-\mathrm{H}$ in the water. Residual organic and hydroxyl groups evident in raw powders were absent in the annealed samples. In this cases (see Fig. 5) copper-oxygen stretching frequencies appeared in the range $550-850 \mathrm{~cm}^{-1}$, associated with the vibrations of $\mathrm{Cu}-\mathrm{O}, \mathrm{Al}-\mathrm{O}$, and $\mathrm{Cu}-\mathrm{O}-\mathrm{Al}$ bonds $[34,39]$. These indicate that the crystal obtained was spinel.

Optical properties of the as-prepared $\mathrm{CuAl}_{2} \mathrm{O}_{4}$ nanocrystals were studied more quantitatively by measuring UV-Vis spectra. The absorption in UV and visible region were rather strong, with an upper limit wavelength at $690 \mathrm{~nm}$ (Fig. 6). The bandgap of $\mathrm{CuAl}_{2} \mathrm{O}_{4}, E_{\mathrm{g}}(\mathrm{eV})$, could be calculated from the absorption limit wavelength $\lambda_{0}(\mathrm{~nm})$, from the equation [40-42]: $\alpha h v=\mathrm{A}\left(h v-E_{\mathrm{g}}\right)^{m / 2}$, where $\alpha$ is the absorption coefficient, $h v$ is the frequency of photons, $A$ is a proportionality constant and $m=4$ for indirect transitions. To determine the band gap we have plotted as function of $\left(h v-E_{\mathrm{g}}\right)$ in (Fig. 6). The band gap of $\mathrm{CuAl}_{2} \mathrm{O}_{4}$ powders obtained from Fig. 6 can be $2.10 \mathrm{eV}$.

With reference to the results, the citric acid as chelatingfuel agent was added to the solution. In other to other paper [43] have two different roles. (1) Citric acid as a chelating agent binds metallic ions $\left(\mathrm{Al}^{3+}\right.$ and $\left.\mathrm{Co}^{2+}\right)$, citric or was applied for formation of complexes for the preparation of $\mathrm{Cu}-\mathrm{Al}$ oxides, and citric acid as a fuel helps to progress the synthesis at relatively low temperatures. However, the role of $\mathrm{pH}$ in the chemistry of ( $\mathrm{Co}$ and $\mathrm{Al})$ gel with different molar ratio of citric acid to cations has being investigated in our laboratory and their results as soon as would be reported.

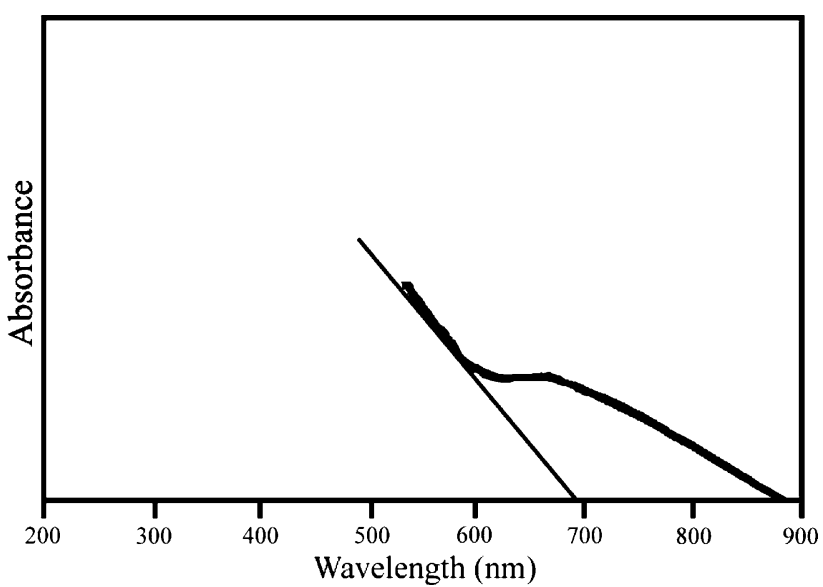

Fig. 6 UV-Visible spectra of $\mathrm{CuAl}_{2} \mathrm{O}_{4}$ nanocrystals synthesized with citric acid and calcined at $800{ }^{\circ} \mathrm{C}$ 


\section{Conclusions}

The proposed modified Pechini method is most powerful for the synthesis of mixed oxides. Spinel $\mathrm{CuAl}_{2} \mathrm{O}_{4}$ nanocrystals were successfully synthesized with $\mathrm{Cu}\left(\mathrm{NO}_{3}\right)_{2}$. $3 \mathrm{H}_{2} \mathrm{O}, \mathrm{Al}\left(\mathrm{NO}_{3}\right)_{3} \cdot 9 \mathrm{H}_{2} \mathrm{O}$ and acid citric by modified solgel method. The lowest temperature for preparation of the pure $\mathrm{CuAl}_{2} \mathrm{O}_{4}$ nanocrystals is about $800{ }^{\circ} \mathrm{C}$. The morphology of as-prepared $\mathrm{CuAL}_{2} \mathrm{O}_{4}$ was quasi-spherical and the dimension was measured to be $17-26 \mathrm{~nm}$. The bandgap, $E_{\mathrm{g}}$, was calculated at $2.10 \mathrm{eV}$ by using the stimulated wavelength limit of $\mathrm{CuAl}_{2} \mathrm{O}_{4}$.

Acknowledgments Authors are grateful to council of University of Kashan for providing financial support to undertake this work.

Open Access This article is distributed under the terms of the Creative Commons Attribution Noncommercial License which permits any noncommercial use, distribution, and reproduction in any medium, provided the original author(s) and source are credited.

\section{References}

1. Cavalcante PMT, Dondi M, Guarini G, Raimondo M, Baldi G (2009) Dyes Pigments 80:226. doi:10.1016/j.dyepig.2008.07.004

2. Ji L, Tang S, Zeng HC, Lin J, Tan KL (2001) Appl Catal Gen 207:247. doi:10.1016/S0926-860X(00)00659-1

3. Bessekhound Y, Trari M (2001) Int J Hydrogen Energy 27:357362. doi:10.1016/S0360-3199(01)00159-8

4. Teng X, Zhuang W, Hu Y, Zhao C, He H, Huang X (2008) J Alloy Comp 458:446. doi:10.1016/j.jallcom.2007.04.013

5. Ryu H, Bartwal KS (2008) Physica B 403:3195. doi:10.1016/ j.physb.2008.04.003

6. Ryu H, Bartwal KS (2008) J Alloy Comp 464:317. doi:10.1016/ j.jallcom.2007.09.100

7. Hong W-S, De Jonghe LC, Yang X, Rahaman MN (1995) J Am Ceram Soc 78:3217. doi:10.1111/j.1151-2916.1995.tb07957.x

8. Valenzuela MA, Jacobs JP, Bosch P, Reijne S, Zapata B, Brongersma HH (1997) Appl Catal A Gen 148:315. doi:10.1016/ S0926-860X(96)00235-9

9. Mimani T (2001) J Alloy Comp 315:123-128. doi:10.1016/ S0925-8388(00)01262-7

10. Zawadzki M, Wrzyszcz J (2000) Mater Res Bull 35:109. doi:10. 1016/S0025-5408(00)00185-9

11. Chen Z, Shi E, Zheng Y, Li W, Wu N, Zhong W (2002) Mater Lett 56:601. doi:10.1016/S0167-577X(02)00561-X

12. Chen Z, Shi E, Li W, Zheng Y, Wu N, Zhong W (2002) J Am Ceram Soc 85:2949. doi:10.1111/j.1151-2916.2002.tb00462.x

13. Adak AK, Pathak A, Pramanik P (1998) J Mater Sci Lett 17:559. doi:10.1023/A:1006521603958

14. Zayat M, Levy D (2000) Chem Mater 12:2763-2769. doi:10. $1021 / \mathrm{cm} 001061 \mathrm{z}$

15. Chemlal S, Larbot A, Persin M, Sarrazin J, Sghyar M, Rafiq M (2000) Mater Res Bull 35:2515. doi:10.1016/S0025-5408(00) 00444-X
16. Guilhaume N, Primet M (1994) J Chem Soc Faraday Trans 90:1541. doi:10.1039/ft9949001541

17. Kurihara LK, Suib SL (1993) Chem Mater 5:609-613. doi: $10.1021 / \mathrm{cm} 00029 \mathrm{a} 006$

18. Wei X, Chen D (2006) Mater Lett 60:823-827. doi:10.1016/ j.matlet.2005.10.024

19. Phani AR, Passacantando M, Santucci S (2001) Mater Chem Phys 68:66. doi:10.1016/S0254-0584(00)00270-4

20. Van der Laag NJ, Snel MD, Magusin PCMM, de With G (2004) J Eur Ceram Soc 24:2417. doi:10.1016/j.jeurceramsoc.2003.06.001

21. Duan XL, Yuan DR, Wang XQ, Xu HY (2005) J Sol-Gel Sci Technol 35:221. doi:10.1007/s10971-005-2359-0

22. Duan XL, Yuan, Sun ZH, Luan CN, Pan DY, Xu D, Lv MK (2005) J Alloy Comp 386:311. doi:10.1016/j.jallcom.2004.05.059

23. Schmidt W, Weidenthaler C (2001) Chem Mater 13:607. doi:10. $1021 / \mathrm{cm} 001138 \mathrm{j}$

24. Areán CO, Mentruit MP, Platero EE, Llabrès i Xamena FX, Parra JB (1999) Mater Lett 39:22. doi:10.1016/S0167-577X(98)00 209-2

25. Platero EE, Areán CO, Parra JB (1999) Res Chem Intermed 25:187. doi:10.1163/156856799X00293

26. Salavati-Niasari M, Davar F (2009) Mater Lett 63:441. doi 10.1016/j.matlet.2008.11.023

27. Salavati-Niasari M, Davar F, Fereshteh Z (2009) Chem Eng J 146:498. doi:10.1016/j.cej.2008.09.042

28. Salavati-Niasari M, Davar F, Mazaheri M (2008) Polyhedron 27:3467. doi:10.1016/j.poly.2008.04.015

29. Merikhi J, Jungk HO, Feldmann C (2000) J Mater Chem 10:1311. doi:10.1039/a910201i

30. Salavati-Niasari M, Davar F, Mazaheri M, Shaterian M (2008) J Magn Magn Mater 320:575. doi:10.1016/j.jmmm.2007.07.020

31. Salavati-Niasari M, Davar F, Mazaheri M (2008) Mater Lett 62:1890. doi:10.1016/j.matlet.2007.10.032

32. Pechini MP (1967) US 3330697

33. Dhak D, Pramanikw P (2006) J Am Ceram Soc 89:1014. doi: 10.1111/j.1551-2916.2005.00769.x

34. Yanyan J, Jinggang L, Xiaotao S, Guiling N, Chengyu W, Xiumei G (2007) J Sol-Gel Sci Technol 42:41. doi:10.1007/s109 71-006-1525-3

35. Li MY, Dong WS, Liu CL, Liu Z, Lin FQ (2008) J Cryst Growth 310:4628. doi:10.1016/j.jcrysgro.2008.08.032

36. Keyson D, Volanti DP, Cavalcante LS, Simões AZ, Varela JA, Longo E (2008) Mater Res Bull 43:771. doi:10.1016/j.materres bull.2007.03.019

37. Joint Committee on Powder Diffraction Standards Diffraction Data File, No. 45-0937, International Centre for Diffraction Data (ICDD, formerly JCPDS) (2000) Newtown Square, PA

38. Jenkins R, Snyder RL (eds) (1996) Chemical analysis: introduction to X-ray powder diffractometry. Wiley, New York, p 90

39. Nakamoto K (1991) Infrared spectra of inorganic and coordination compound, 4th edn. Chemical Industry Press, Beijing

40. Lin H-H, Wang C-Y, Shih HC, Chen J-M, Hsieh C-T (2004) J Appl Phys 95:5889. doi:10.1063/1.1690114

41. Wang $\mathrm{H}, \mathrm{Xu} \mathrm{J}-\mathrm{Z}$, Zhu J-J, Chen H-Y (2002) J Cryst Growth 244:88. doi:10.1016/S0022-0248(02)01571-3

42. Kaur M, Muthe KP, Despande SK, Choudhury S, Singh JB, Verma N, Gupta SK, Yakhmi JV (2006) J Cryst Growth 289:670. doi:10.1016/j.jcrysgro.2005.11.111

43. Saberi A, Golestani-Fard F, Sarpoolaky H, Willert-Porada M, Gerdes T, Simon R (2008) J Alloy Comp 462:142. doi:10.1016/ j.jallcom.2007.07.101 